\title{
Propuesta de diseño de alojamientos rurales indígenas en la comunidad Nasa-Páez en Toribío, Cauca. Turismo y cultura en el posacuerdo*
}

DOI: https://doi.org/10.18046/recs.i28.2568

\begin{abstract}
Design of Indigenous Rural Lodgings in the Nasa-Páez Community, Toribio-Cauca. Tourism and Culture in the Post-Agreement

Proposta de projeto de habitação rural indígena na comunidade Nasa-Páez em Toribío, Cauca. Turismo e cultura no pós-acordo
\end{abstract}

\author{
Tomás Bolaños-Silva ${ }^{\star *}$ \\ Julián Ricardo Ruiz-Solano ${ }^{* * *}$ \\ María Patricia Farfán-Sopó ${ }^{* * *}$ \\ Juan David González-Vallejo ${ }^{* * * *}$ \\ Valeria Daniela Ruiz-Triana ${ }^{* * * * *}$ \\ Universidad Piloto de Colombia (Bogotá)
}

\begin{abstract}
* Proyecto financiado por la Universidad Piloto de Colombia. Artículo de investigación recibido el 09-11-2017 y aprobado el 09-04-2019.

${ }^{* *}$ Magíster en Gestión Ambiental de la Pontificia Universidad Javeriana. Biólogo. Profesor investigador del Laboratorio de Ambientes Sostenibles, programa de Arquitectura, Universidad Piloto de Colombia. Catedrático, Facultad de Estudios Ambientales y Rurales, Pontificia Universidad Javeriana. Correo electrónico: tomas-bolanos@unipiloto.edu.co ORCID: https://orcid.org/oooo-0oo2-5527-1495

*** Magíster en Gestión Urbana de la Universidad Piloto de Colombia. Arquitecto. Profesor investigador del Laboratorio de Urbanismo, programa de Arquitectura, Universidad Piloto de Colombia. Correo electrónico: julian-ruiz@upc.edu.co ORCID: https://orcid.org/oooo-ooo1-5461-7143
\end{abstract}

**** Candidata a PhD en Arquitectura de McGill University. Magíster en Arquitectura de McGill University. Arquitecta de la Universidad Piloto de Colombia. Decana administrativa, programa de Arquitectura. Investigadora del Laboratorio de Ambientes Sostenibles, Universidad Piloto de Colombia. Correo electrónico: pfarfan@unipiloto.edu.co ORCID: https://orcid.org/oooo-0oo3-2458-8657

***** Estudiante del programa de Arquitectura. ORCID: https://orcid.org/oooo-ooo3-4335-2922

****** Estudiante del programa de Arquitectura. ORCID: https://orcid.org/oooo-ooo2-3281-7184 


\section{Cómo citar/How to cite}

Bolaños-Silva, Tomás; Ruiz-Solano, Julián Ricardo; Farfán-Sopó, María Patricia; González-Vallejo, Juan David; Ruiz-Triana, Valeria Daniela (2019). Propuesta de diseño de alojamientos rurales indígenas en la comunidad Nasa-Páez en Toribío, Cauca. Turismo y cultura en el posacuerdo. Revista CS, 28, 229-257. https://doi.org/10.18046/recs.i28.2568 
Resumen

Abstract

Resumo

El diseño de alojamientos turísticos rurales indígenas en el municipio de Toribío cobra importancia en el posacuerdo, debido a las alternativas de desarrollo turístico en territorios que vivieron el conflicto armado. Se proponen tres tipos de alternativas en una intervención gradual en asentamientos indígenas tradicionales, partiendo de la adecuación de una habitación, hasta la construcción de un módulo independiente, con el fin de incentivar la exploración de este tipo de servicios. Estos diseños se generan a partir de la consulta a grupos encargados de la planeación del turismo en Totibío, para respetar los aspectos de su cosmovisión y cultura.

PALABRAS CLAVE:

diseño participativo, alojamiento rural, turismo, indígena, posacuerdo

Designing indigenous rural tourist accommodations in Toribío-Cauca (Colombia) becomes relevant in the framework of the post-agreement due to the alternatives for touristic development in territories that experienced the armed conflict. Three types of alternatives are proposed for a gradual intervention in traditional indigenous settlements, starting from the adaptation of a room, until the construction of an independent module, with the purpose of developing tourist services. These designs arise from consultation with the tourist planning groups in Toribío to preserve the worldview and culture of this territory.

KEYWORDS:

Participatory Design, Rural Lodging, Tourism, Indigenous, Peace Agreement

O projeto de alojamento turístico rural indígena no município de Toribío torna-se importante no pós-acordo, devido ás alternativas de desenvolvimento do turismo nos territórios que viveram o conflito armado. Propõem-se três tipos de alternativas em 
uma intervenção gradual em assentamentos indígenas tradicionais, começando com a adaptação de uma sala, até a construção de um módulo independente, a fim de incentivar a exploração desse tipo de serviço. Esses projetos são gerados a partir de grupos de consultoria responsáveis pelo planejamento do turismo em Toribío, para respeitar os aspectos de sua visão de mundo e cultura.

PALAVRAS-CHAVE:

desenho participativo, alojamento rural, turismo, indígena, pós-acordo 


\section{Introducción}

Este documento presenta los resultados de la investigación sobre Paisaje Cultural Andino del programa de Arquitectura de la Universidad Piloto de Colombia que, desde 2015, ha acompañado a la comunidad indígena Nasa-Páez del norte del Cauca, la cual abrió sus puertas y permitió estrechar su relación con la academia, para la interpretación, análisis y apoyo a procesos en la producción social del hábitat, con diferentes espacios de investigación y comunicación de los saberes y conocimientos, bajo el respeto de la ley de origen y la espiritualidad propia. En este marco de trabajo, se identificó la oportunidad y la necesidad puntual de la comunidad de fortalecer sus acciones orientadas a un desarrollo de turismo comunitario que, inicialmente, busca resaltar el potencial de su patrimonio étnico y natural representado en su territorio por su cosmovisión, los diferentes pisos térmicos, ecosistemas naturales y paisajes productivos andinos.

Actualmente, en el marco de los acuerdos de paz, se promulga la necesidad de proponer estrategias de turismo que permitan, a los territorios y comunidades que fueron víctimas del conflicto, generar alternativas de ingresos. Según el comunicado publicado en la página web del Ministerio de Comercio, Industria y Turismo ((MINCIT), 2017), de la ministra María Claudia Lacouture: "el posconflicto representa grandes oportunidades y retos para las comunidades y el turismo comunitario constituye una alternativa de desarrollo que genera beneficios económicos a las comunidades, preservación de los recursos naturales y valorización del patrimonio cultural". Bajo este panorama, la comunidad Nasa-Páez del municipio de Toribío, Cauca, busca abrir su territorio a nuevas actividades de carácter económico; en este caso, específicamente, al desarrollo de infraestructura para el turismo acorde a las condiciones y características de un territorio indígena, colmado de múltiples bienes tangibles e intangibles, considerados patrimonio cultural por sus valores excepcionales y únicos, preservados hoy en día gracias a la comunidad local.

Las comunidades del norte del Cauca, específicamente de los resguardos de Toribío, San Francisco y Tacueyó, han trabajado en temas de turismo en sus territorios desde hace más de cuatro años, momento en el cual comenzó a mejorar la situación de orden público, según Marco Tulio Jascué (comunicación personal, 22 de octubre, 2016) -guardia indígena y líder del grupo turístico asociativo Mi Finquita-, buscando el bienestar de sus comuneros y el cuidado de la naturaleza. Entre sus proyectos, se encuentran diversas rutas turísticas que incluyen escenarios de belleza paisajística y connotaciones culturales, como el ritual del Saakhelu (Figura 1); sin embargo, el tema de la construcción de alojamientos y el ordenamiento de los mismos no es muy claro, como afirma Alcibiades Escue Musicue (comunicación personal, 15 de marzo, 2017), alcalde de Toribío. 
FIGURA 1 | Ritual Mayor del Saakhelu, Tacueyó-Toribío, Cauca

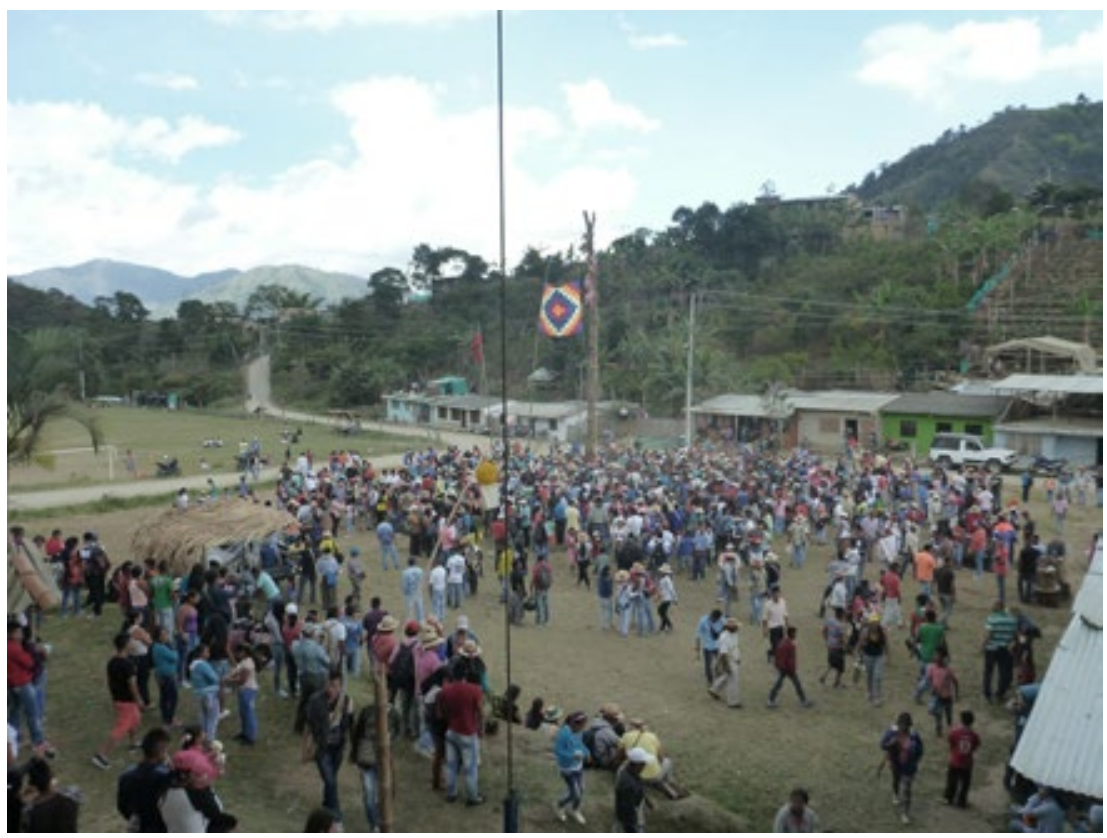

Foto: Tomás Bolaños Silva, 2016

En concordancia con lo anterior, y con la idea de brindar herramientas que faciliten la implementación de un modelo turístico para el municipio de Toribío, el presente documento tiene como objetivo el desarrollo de propuestas de diseño para alojamientos que sirvan al modelo turístico que actualmente se gestiona e implementa por parte de la comunidad indígena, proporcionando soporte a la iniciativa que se adelanta para la conformación de un modelo turístico en el territorio.

Bajo la premisa de dar cumplimiento a este objetivo, se plantea, consecuentemente, el desarrollo de dos objetivos específicos. Primero, la propuesta de conformación de criterios para el establecimiento de los determinantes de diseño para alojamiento rural indígena, construidos a partir de las interrelaciones con la comunidad e identificación de elementos relevantes en su discurso, para llegar al desarrollo del segundo objetivo específico, que busca brindar opciones de intervenciones para el desarrollo del turismo, mediante alojamientos y otros servicios, concordantes con la información consolidada del primer objetivo específico. 


\section{Vinculando la arquitectura y el turismo}

La arquitectura, mediante obras icónicas, evidencia la presencia y aporte humano para la construcción social del territorio, la creación de patrimonios (MINCIT, 2015a) y la relación entre saberes de la comunidad indígena y la academia occidental. Por lo tanto, se entiende el patrimonio como el legado que es entregado por el pasado, vivenciado en el presente y que se desea trasmitir a futuras generaciones; se presenta como una fuente insustituible de vida e inspiración, portadora de valores culturales únicos (Organización de las Naciones Unidas para la Educación, la Ciencia y la Cultura, 2017).

La arquitectura indígena, con sus técnicas y materiales adaptativos a su entorno natural, se considera como parte esencial de la cultura y como parte del patrimonio que, tanto material como inmaterial (significado espiritual en el marco de ley de origen), es reconocido a nivel local y se pretende evidenciar a los visitantes. Estos bienes tangibles e intangibles hacen del patrimonio cultural merecedor de un trato especial, en beneficio de su protección y conservación dado su alto contenido simbólico, y abre el siguiente cuestionamiento: ¿cómo se vincula la arquitectura a la gestión que se pueda hacer de este?

Esta pregunta orienta la reflexión respecto a la correlación que se presenta entre el patrimonio cultural y su utilización turística, siendo una relación compleja desde diversos puntos de vista, pero inevitable por las actuales dinámicas sociales, políticas y económicas de un entorno influenciado por la globalización y los proceso de mercantilización. El turismo se presenta, para el patrimonio cultural, como un fenómeno socioeconómico que puede proveer beneficios y problemáticas para el mismo, dependiendo del modelo, abordaje y gestión turística que se implemente, así como de los conocimientos y los valores que la comunidad indígena asigne a esta actividad (Bolnick, 2003; Pedersen, 2005; Velazco, 2009).

Un punto de encuentro entre arquitectura y turismo puede ser el momento en el cual la gestión turística y la del patrimonio coinciden y son mutuamente benéficas, pues buscan una experiencia para el visitante; esto se da a partir de la transformación de bienes patrimoniales en recursos turísticos, claramente sin perder el objetivo de conservar y proteger el legado que representan y, por el contrario, buscando su contribución en la difusión de la importancia de la identidad local, mediante relaciones entre bienes patrimoniales y el contexto socioeconómico. Desde los aspectos ambientales, se busca el menor impacto sobre el patrimonio natural, en el marco de una gestión integral que contemple los beneficios y problemas que conlleva el surgimiento de espacios con nuevas dinámicas y valores culturales en un territorio ancestral (Cardet-Fernandez; González; Palao, 2017; Ospina-Niño, 2017; Velazco, 2009). 


\section{Hacia un desarrollo turístico del territorio Nasa-Páez: patrimonio cultural y turismo Nasa-Páez}

Los Nasa-Páez son un pueblo indígena de la zona andina colombiana, en los departamentos del Cauca (principalmente), Valle del Cauca, Tolima, Putumayo y Huila, entre otros. Con la llegada de los españoles, en el siglo XVI, mostraron una dura resistencia, y hoy en día mantienen una sólida defensa de su territorio (Docentes Comunidad Nasa, 2014).

La comunidad Nasa-Páez reconoce y valora su territorio como patrimonio cultural, lo cual permite que los bienes conserven su capacidad simbólica y transmitan sus valores a turistas, a pesar de la modificación del uso original del patrimonio; sin embargo, surge el peligro de perder autenticidad por la falta de reinversión de los bienes logrados por el turismo en los bienes patrimoniales (Velazco, 2009).

Según Velazco (2009), para poder analizar estas problemáticas, se requiere tener conocimiento de la fuerte dificultad que presenta la gestión turística del patrimonio cultural, contrastando el sector turístico y el patrimonial, dado su origen, naturaleza y finalidad; $y$ a pesar de que ambos puedan llegar a tener intereses comunes, igualmente poseen amplias diferencias en su posible sociedad.

Inicialmente, es necesario entender que ambos sectores están bajo la influencia y mutación guiada por la concepción social de los términos cultura y turismo, siendo determinantes al momento de poder abordar modelos operacionales que sirvan al pensamiento contemporáneo. Además, debe tenerse en cuenta que, actualmente, el turismo se presenta como una actividad cada vez más demandante, donde el patrimonio adquiere protagonismo, lo cual genera panoramas de desencuentro para la conciencia ambiental y la apreciación cultural que el patrimonio cultural abandera (Velazco, 2009; Zanirato; Tomazzoni, 2015).

En segunda instancia, el turismo y la gestión patrimonial son ámbitos de actividad concebidos bajo marcos conceptuales disimiles, respondiendo a criterios, valores y opiniones diversas. El turismo se muestra como un escenario prioritario, dentro del sector privado, para el desarrollo económico; diferente al sector patrimonial, donde el gestor es el sector público en busca de beneficios de orden social, evidenciándose como agentes con diferentes finalidades. En este orden de ideas, en el caso de los usuarios, se presenta una situación similar, encontrando cómo los destinatarios tradicionales responden a perfiles diferenciados según su motivación, ya sea de turista, visitante o consumidor cultural, según expone Velazco (2009).

En tercer orden, se identifica cómo los dos sectores conciben los bienes patrimoniales bajo valores diferentes, donde el turismo entiende el bien patrimonial como un valor de uso (consumo) que aporta autenticidad, siendo un elemento de interés 
en un determinado espacio; en contraposición al sector patrimonial, que le otorga al bien un valor simbólico (conservación) y representativo para una comunidad o cultura (Herrera, 2017; Velazco, 2009).

Estos tres factores orientan las dinámicas y convergencias que se desarrollan entre el patrimonio y el turismo, las cuales se analizan desde los diferentes agentes e intereses. Por un lado, los privados, que innovan y diversifican el producto acorde al mercado, de donde surge la oportunidad de consumir cultura por la distinción que otorga, convirtiendo al turismo cultural en un producto de interés. Por su parte, el sector público percibe el aumento imparable de gastos públicos para el mantenimiento de todas la acciones que impulsa el turismo cultural, permitiendo la supervivencia de los bienes patrimoniales y llevando al sector público a evaluar las fuentes de financiación complementaria que mitiguen la reducción en los fondos públicos.

Lo anterior permite inferir cómo los diferentes agentes comienzan a ver la importancia de uno en el otro, trabajando, de forma general, por la sostenibilidad del sector y definiendo cómo se comienzan a articular entorno a un espacio en el que se desarrolla su actividad (Giedelmann; Rueda, 2013; Herrera, 2017; Llontop, 2017; Velazco, 2009; Zanirato; Tomazzoni, 2015). Este panorama conlleva a pensar en la futura consolidación de valores del sistema de bienes patrimoniales en el turismo, como construcción de una conciencia que defienda el medio ambiente y coexista con la rentabilidad económica, administrando de manera eficiente la convivencia con prioridad en la conservación patrimonial y cultural.

\section{La planificación para un desarrollo sostenible del turismo cultural}

Sin ánimo de analizar exhaustivamente ni reflexionar sobre los instrumentos de gestión o técnicas de planificación, es posible analizar algunos de los enfoques que Velazco (2009) centra en la conceptualización del bien, el diseño y planificación en cuestiones operativas y funcionales del ámbito turístico en contextos patrimoniales.

La planificación define lineamientos de acción que, en el caso de la comunidad Nasa-Páez, buscan el impulso e implementación de actividades turísticas, y la oferta de múltiples servicios que permitan el desarrollo de bienes diseminados por el territorio, impulsándolo como destino turístico en los bienes patrimoniales y culturales. Las maneras de asumir estos objetivos pueden ser cambiantes en el tiempo, marcadas por ideas y prácticas que surgen de diversos campos, en consecuencia con el mercado y requerimiento de los usuarios. 
La gestión turística en ámbitos patrimoniales debe de conllevar un proceso de reflexión previo a cualquier acción, lo que obliga a la conformación de un esquema de planificación donde se aborde un análisis del estado actual, un diagnóstico de las problemáticas y potencialidades para, posteriormente, identificar y construir objetivos, en respuesta y relación a los pasos anteriormente señalados, permitiendo el diseño de las líneas de acción para alcanzar dichos objetivos, definidos por actuaciones, prioridades y recursos (Giedelmann; Rueda, 2013; Velazco, 2009).

Los planes de gestión turística deben diseñarse participativamente y en continua retroalimentación con los agentes encargados de su implantación (pobladores locales) y los destinatarios de las acciones (pobladores y visitantes), de manera que puedan convivir sosteniblemente mediante sus acciones sociales y ambientales. Igualmente, la toma de decisiones debe proporcionar libertad en la construcción de la imagen y el carácter del territorio que se proyectan al exterior, donde es presentado a la vista de futuros usuarios (Arnoult, 2010; Bernardino; Freitas, 2017; Velazco, 2009).

\section{Aspectos del contexto para la reflexión}

En los territorios rurales de Colombia, la habitabilidad y el desarrollo prevalecen en la incertidumbre, al permanecer inmersos en múltiples factores, entre ellos, la presencia de grupos al margen de la ley, el despojo de tierras y la vulnerabilidad natural del territorio, situaciones de pobreza extrema, vulneración de derechos fundamentales y destrucción de recursos naturales. El futuro de un territorio que contiene elementos suficientes para garantizar la soberanía y seguridad alimentaria, calidad de vida y habitabilidad, entre otros, aunque puede ser bueno, no necesariamente puede brindar bienestar a las comunidades a partir del estado de los sistemas que soportan la vida, principalmente desde las interacciones entre los diversos actores (locales y externos) y los diferentes intereses económicos que allí se generan, como lo manifiesta Luis Antonio Poto (comunicación personal, 23 de febrero, 2015), indígena nasa, líder de proyectos comunitarios Toribío-San Francisco.

El turismo no siempre significa bienestar para las comunidades que lo prestan, sino que puede, por el contrario, traer diversos problemas relacionados con el intercambio cultural, el cual, en ocasiones, puede ser asimétrico, debido a los contenidos de esta actividad, que pueden ser tan inocentes como llevar dulces a los niños de una comunidad indígena o mostrar unos modos de vida que no son acordes para un territorio rural. De esta manera, el turismo generará cambios que pueden ser positivos o negativos, reversibles o no, y que generan el deterioro del territorio, desde la pérdida de la cultura local, hasta el agotamiento de los recursos naturales o 
desaparición de ecosistemas, con el consecuente abandono de los turistas y la caída de ingresos para las comunidades (Asensio; Pérez, 2012; Maldonado, 2006; Marín; García; Daltabuit, 2012; Pereiro, 2013).

Sin embargo, el crecimiento del turismo no necesariamente va hacia la terminación del conflicto, pues se necesita acompañamiento y compromiso por las partes. El MINCIT (2015b) propone la estrategia de turismo y paz a partir de tres ejes, en los cuales se resalta lo siguiente, en el marco de necesidades de infraestructuras turísticas para el territorio:

1. Construcción de tejido social: busca la confianza comunidades-Estado, con el encadenamiento turístico productivo, a partir del respeto de derechos, atención, reparación, reintegración y, específicamente, lo relacionado con las dinámicas del territorio, muy acorde con la cosmovisión Nasa-Páez frente al reconocimiento, apropiación, valoración y desarrollo ordenado de los territorios y la dignificación de las comunidades.

2. Transformación y desarrollo de entornos de paz: busca empoderamiento comunitario y el arraigo del territorio, a partir de los modelos de negocios turísticos que favorezcan la convivencia pacifica, asociaciones productivas, cambio de paradigmas sobre el territorio, y el turismo como nueva fuente de ingresos.

3. Sostenibilidad: el más importante, relacionado con la forma de ocupar y utilizar el territorio como escenario turístico, a partir del aprovechamiento y uso adecuado de los recursos naturales, por parte de la comunidad (materiales de construcción locales, respeto y conservación de prácticas culturales, mejoramiento de calidad de vida, $y$ prácticas turísticas incluyentes y equitativas).

Como se mencionó anteriormente, el turismo constituye un factor de desarrollo económico local, donde la globalización fortalece la prestación de servicios relacionados con el territorio y la cultura, situando al turismo como productor de bienes inmateriales y compensadores de actividades agrícolas o industriales desfasadas en los municipios rurales, según explica José Ojeda (2004).

\section{Metodología}

El trabajo parte de la concepción que los indígenas del cauca tienen sobre la universidad y la investigación, a fin de lograr la integración entre investigadores y comunidad. Para ellos, se trata de "gente pensando" desde realidades, visiones de los pueblos y la autonomía territorial, entendida como "la capacidad de decidir en cuanto a lo que nosotros pensamos, en cuanto a lo que nosotros planeamos" (Levalle; Levin, 
2011), donde el territorio se conoce de la mano de los mayores y la orientación de los espíritus (Levalle; Levin, 2011). Por otra parte, la investigación del pueblo Nasa-Páez se orienta desde cuatro pasos: 1) el reconocimiento y apropiación del mundo espiritual; 2) el diálogo y la concertación con las autoridades propias; 3) la consulta con los Thë walas; y 4) la participación comunitaria (Centro de Educación, Capacitación e Investigación para el Desarrollo Integral de la Comunidad (CECIDIC), 2015).

Las experiencias de integración Nasa-academia se abordan desde el grupo de investigación, a partir de tres mingas del conocimiento (2015-2017) y dos seminarios de hábitat, ecoterritorio, espacio y construcción (2016-2017), en los cuales han participado, de manera libre, habitantes del territorio e investigadores. En estas mingas y seminarios se recorre el territorio, se dialoga, se escucha y se atienden los mensajes que, desde la comunidad (autoridades propias, mayores-Thë wala y comuneros), se orientan a partir de lo que piensan y lo que planean. En este recorrido, se participó en el ritual mayor del Saakelu, en 2016, para vivir la visión y espiritualidad de la relación sociedad-naturaleza, el pensar y el sentir indígena, a partir de las preguntas orientadoras Nasa: ¿Cómo involucrar en esta investigación propia el sentir, la espiritualidad y la naturaleza?, ¿cómo investigar con y para la naturaleza, y no someterla como objeto de estudio y destrucción? (CECIDIC, 2015).

Para el desarrollo de este proyecto, se orientó la metodología desde la investigación-acción participativa, con el objetivo de indagar y generar una postura crítica-reflexiva frente a las necesidades y percepciones de la comunidad para el desarrollo de alojamientos turísticos rurales de Toribío-Tacueyó.

Gracias a la información empírica -manejada por la comunidad indígena-, la visita y la colaboración continua, desde el año 2015, se logró identificar el tema y establecer el contacto con los principales actores encargados del turismo local en el resguardo. Para establecer la estrategia de recolección de información (en los años 2016-2017), se participó en los rituales y vivencias en el territorio, a partir de seminarios y mingas, en los cuales, mediante un conjunto de preguntas realizadas en las conversaciones, se recopiló información cualitativa, partiendo de los intereses particulares del grupo encargado de las iniciativas de turismo local. Las personas de la comunidad fueron seleccionadas por recomendaciones de los líderes de la comunidad, por ser los encargados de las actividades relacionadas con el desarrollo turístico y comunitario. Lo anterior permitió una visión de la memoria oral para una posterior reflexión conjunta frente a los elementos constitutivos y los determinantes de diseño del alojamiento, como un espacio que aporte bienestar y funcionalidad en los predios rurales.

Mantener el respeto por la autodeterminación y la cosmovisión de los grupos de turismo de Toribío requiere una propuesta de alojamientos que contemple las visiones 
propias del territorio y las formas ancestrales, las cuales, particularmente en el norte del Cauca, son un testimonio de la permanencia en el lugar y la lucha por la recuperación de sus tierras y cultura, sin olvidar los requerimientos de alojamiento rural de la NTSHoo8. Se privilegia la arquitectura vernácula, por su representación de los aspectos culturales, y la visibilización de hitos materiales y arquitectónicos, entre otros.

\section{Relación arquitectura, territorio y turismo}

A partir de las visitas al territorio desde el año 2015 (Figura 2), se pudo identificar, entre las diversas necesidades de la comunidad, el interés creciente frente al desarrollo del turismo en las veredas, inicialmente por turistas locales indígenas de otros municipios cercanos y algunos no locales, tanto nacionales como internacionales, como lo expresan el mayor Maximiliano Paví (comunicación personal, 23 de febrero, 2015), del resguardo de San Francisco, y el señor exalcalde de Toribío, Ezequiel Vitonás (comunicación personal, 16 de marzo, 2016).

FIGURA 2 Recorridos por el territorio (departamento del Cauca)

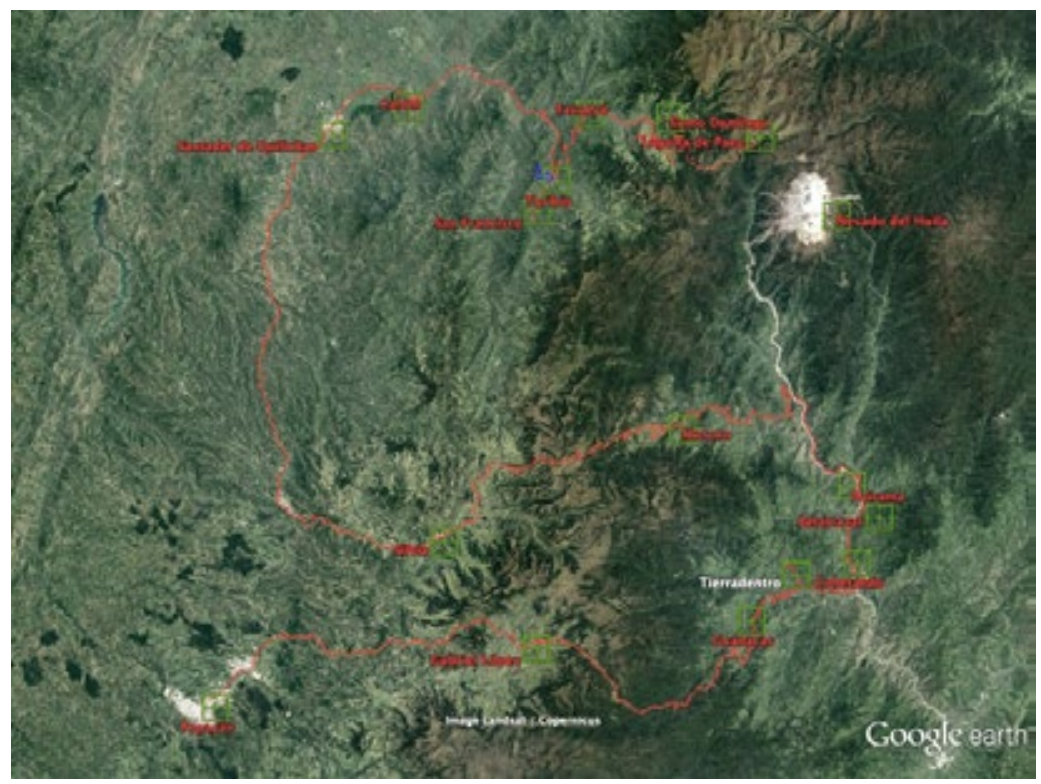


En rituales como el Saakhelu, del año 2016 en Tacueyó, se pudo evidenciar la presencia de visitantes de Europa y de diferentes regiones colombianas; los procesos de paz en el territorio han permitido que los visitantes puedan aventurarse a este lugar, para buscar nuevas experiencias desde diferentes intereses, pero, principalmente, el conocimiento de la cultura local (M. T. Jascue; L. A. Poto, comunicación personal, 16 de marzo, 2016). En este orden de ideas, la comunidad local inició proyectos para el desarrollo turístico, mediante apoyo de consultores (capacitaciones en turismo), siendo el tema de alojamientos no tan prioritario, buscando comprender los determinantes del turismo del Valle del Cocora, tal vez por la presencia de las palmas de cera en el sector de Santo Domingo y de la vereda López (Figura 3). Sin embargo, en los diferentes escenarios se menciona la imposición de gastronomía no propia para satisfacer las necesidades alimentarias del visitante, subvalorando la gastronomía local. Por otra parte, les proponen diseños de alojamientos tipo chalet suizo, en parte por el paisaje montañoso, pero que no corresponden a la realidad cultural local.

FIGURA 3 Palmas de cera y arquitectura vernácula, vereda López, Toribío

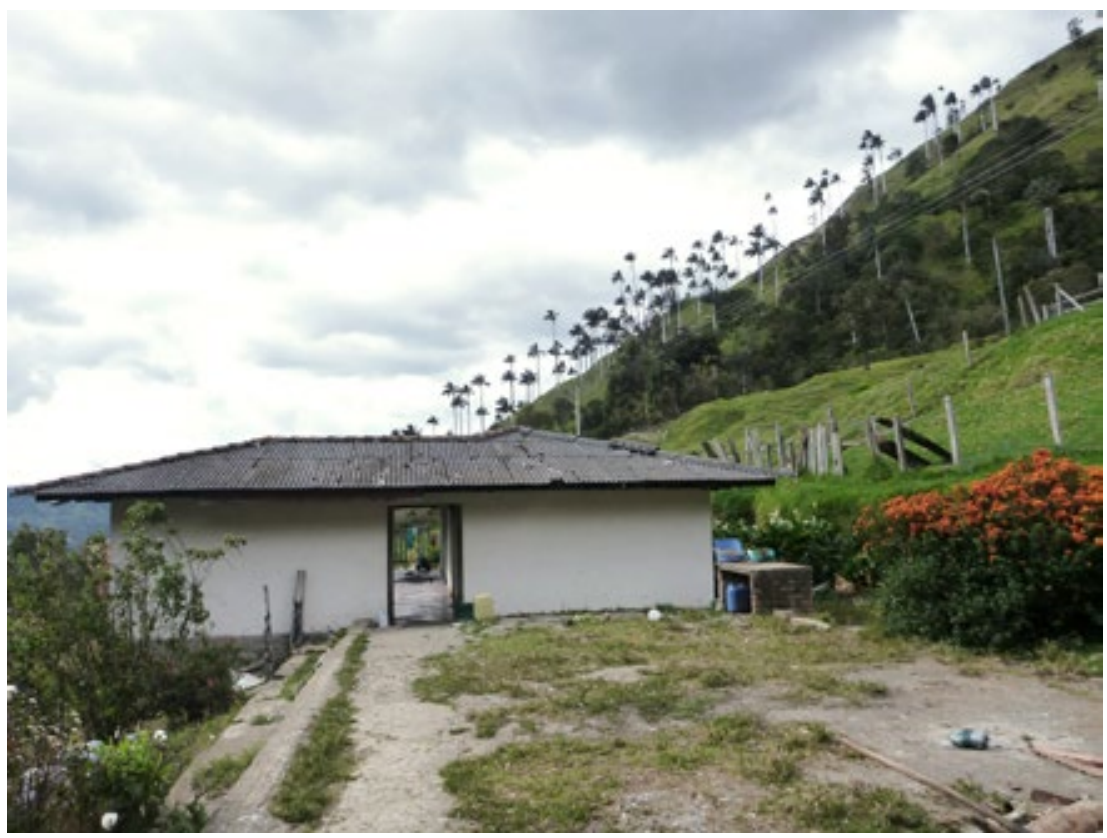


Durante 2016 y 2017, los sabios líderes espirituales y el resguardo-cabildo, decidieron no avalar diseños exógenos a la cultura (M. T. Jascue, comunicación personal, 16 de marzo, 2016) y se propuso respetar los diseños propios de la arquitectura vernácula, con el uso de materiales y técnicas de construcción acompañados de rituales propios (Figura 4). Este ejercicio permitió la reflexión frente a este tema, identificando tres tipologías básicas, y unos espacios y materiales fundamentales.

FIGURA 4 Materiales y técnicas locales, Resguardo de San Francisco, Toribío

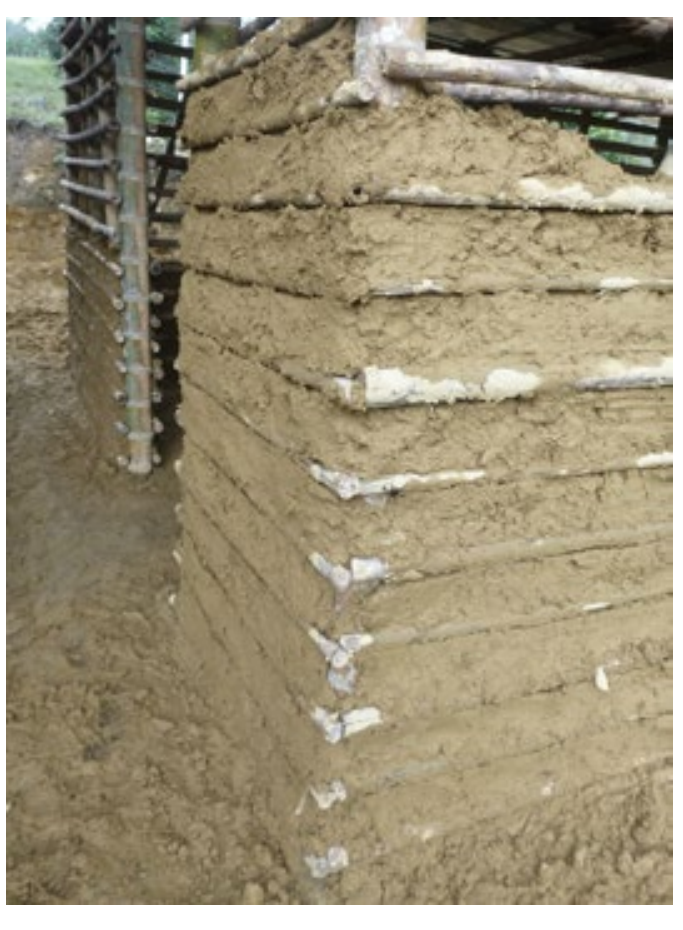

Foto: Tomás Bolaños Silva, 2016

Por lo tanto, estructurar el modelo de desarrollo turístico anteriormente expuesto debe involucrar particularidades étnicas y sistemas de manejo comunitario como los resguardos indígenas, donde se vele por la sostenibilidad. Para esto, es necesario incluir, en la planificación y el desarrollo de los programas y servicios turísticos, la identidad, la naturaleza del territorio y la cultura local, así como lo expresado por la comunidad indígena en los diferentes espacios participativos. 
Los aspectos antes mencionados pueden considerarse, desde la identificación, reconocimiento y apropiación de elementos, patrimoniales (declarados o no), teniendo también en cuenta aquellos potenciales, al estar ubicados en la cordillera central con numerosos accidentes geográficos, valles estrechos, cañones, pequeñas terrazas y ríos caudalosos, junto a formaciones geológicas contiguas de gran altura como el Nevado del Huila, un lugar concebido por los Nasa-Páez como la casa donde viven todos y que enmarca espacios sagrados, concordantes a su mitología y cosmogonía. Esta apropiación social de los elementos patrimoniales redunda en la percepción comunitaria de una fuente de beneficios colectivos (p. e. visitar el cerro Berlín en una caminata guiada evidencia elementos patrimoniales del territorio, si los guías e intérpretes los conocen y comprenden), consolidando nuevas relaciones entre la comunidad, el turismo y su territorio (Ministerio de Cultura, 2010).

El turismo, como actividad novedosa en el municipio, obliga a la creación y articulación de diferentes relaciones de base, para el funcionamiento e implementación del modelo turístico. Inicialmente, se requiere un territorio que posea las condiciones cualitativas y cuantitativas idóneas para su desarrollo, acompañado de valores agregados que marquen diferenciadores en la oferta turística y permitan la consolidación de nuevos núcleos para la visita de viajeros, los cuales están dispuestos a vivir una experiencia étnica, con altos niveles culturales, tanto nacionales como internacionales. Consecuentemente, dicho territorio requiere el desarrollo de infraestructura y una adecuación que permita el adelanto y funcionamiento de actividades turísticas, respondiendo a la vocación y los objetivos planeados en el modelo turístico, al igual que a requerimientos del mercado (guías bilingües, gastronomía, senderos para ecoturismo, interpretación ambiental, entre otros aspectos culturales).

El desarrollo de actividades turísticas dentro del territorio debe denotar calidad y sostenibilidad medioambiental, mediante objetivos que impulsen instalaciones adecuadas, alojamientos tradicionales que preserven las costumbres ancestrales, actividades sustentables y respetuosas con la estructura ecológica y los valores culturales propios de la región, aunque debe seguir siendo relevante el fomento de experiencias culturales y sociales únicas que favorezcan el disfrute de los recursos naturales y patrimoniales, proporcionando elementos diferenciadores dentro de las alternativas de tipos de turismo existentes (Ojeda, 2004).

En este punto, la arquitectura entra a funcionar como engranaje conector de la actividad turística y el territorio, permitiendo la implementación de infraestructura que brinde nuevas actividades en un territorio aislado, bajo parámetros de intervención respetuosos con el medio ambiente y la cultura local, consolidando un entorno para el desarrollo socioeconómico con garantías al patrimonio cultural presente bajo parámetros de sostenibilidad. Por esta razón, se propone la implementación 
de alojamientos y módulos de servicios, para el uso del turista, que preserven las cualidades tipológicas tradicionales Nasa-Páez, respetando la baja densidad con la cual se ha ocupado tradicionalmente el territorio.

Es, entonces, cuando surge la necesidad de establecer una reflexión frente a las necesidades de los tipos de alojamiento en las comunidades indígenas, específicamente en el norte del Cauca (Toribío-Tacueyó), más allá de considerar el modelo de desarrollo económico turístico (clúster, tipos de turismo, servicios, entre otros). En torno a esta reflexión, es necesario crear criterios que brinden lineamientos en la toma de decisiones, al momento de diseñar los alojamientos que serán implantados en un contexto.

\section{Criterios para el establecimiento de los determinantes de diseño para alojamiento rural indígena}

Los aspectos para el diseño de alojamientos rurales en Colombia se determinan en la NTSH oo8, la cual es amplia en lo referente al ámbito rural. Aunque existe bibliografía para este tipo de desarrollo, en general no se centra en las particularidades del alojamiento en comunidades indígenas, específicamente para Colombia.

Para esto, de la mano con los actores locales (grupos de turismo del municipio), con la vivencia en el territorio de los tipos de viviendas, materiales y otros elementos pertinentes, se ha diseñado una propuesta de criterios orientados al establecimiento de los determinantes de diseño para el alojamiento rural indígena.

Se agrupan en tres temáticas y 15 aspectos para la gestión del diseño de alojamientos turísticos rurales indígenas, los cuales se enlistan a continuación: \begin{tabular}{|l|l} 
TABLA 1 & $\begin{array}{l}\text { Aspectos para gestión del diseño de alojamientos turísticos } \\
\text { rurales indígenas }\end{array}$
\end{tabular}

\begin{tabular}{|c|c|c|}
\hline Temática & Aspecto & Posibles descriptores \\
\hline \multirow{2}{*}{$\begin{array}{l}\text { 1. Generalidades } \\
\text { del turismo }\end{array}$} & $\begin{array}{l}\text { Expectativas frente al tipo de } \\
\text { turismo en el territorio }\end{array}$ & Naturaleza, cultural, masivo \\
\hline & Tipo de visitante & $\begin{array}{l}\text { Sofisticado, que entienda la cultura, no depreda- } \\
\text { dor, dispuesto a pagar, masivo }\end{array}$ \\
\hline \multirow{3}{*}{$\begin{array}{l}\text { 2. Culturales } \\
\text { generales }\end{array}$} & $\begin{array}{l}\text { Aspectos culturales/rituales } \\
\text { intocables, no negociables }\end{array}$ & $\begin{array}{l}\text { Acceso a lugares sagrados (ecosistemas, estructu- } \\
\text { ras), ritos privados }\end{array}$ \\
\hline & $\begin{array}{l}\text { Aspectos culturales para divulgar } \\
\text { y que el turista aprenda }\end{array}$ & $\begin{array}{l}\text { Rituales, lengua, relación sociedad- naturaleza, } \\
\text { sistemas productivos comunitarios }\end{array}$ \\
\hline & $\begin{array}{l}\text { Aspectos culturales relacionados } \\
\text { con artes y oficios }\end{array}$ & Artesanías, música, folklore, gastronomía \\
\hline
\end{tabular}


246 Tomás Bolaños-Silva • Julián Ricardo Ruiz-Solano • María Patricia Farfán-Sopó • Juan David González-Vallejo • Valeria Daniela Ruiz-Triana

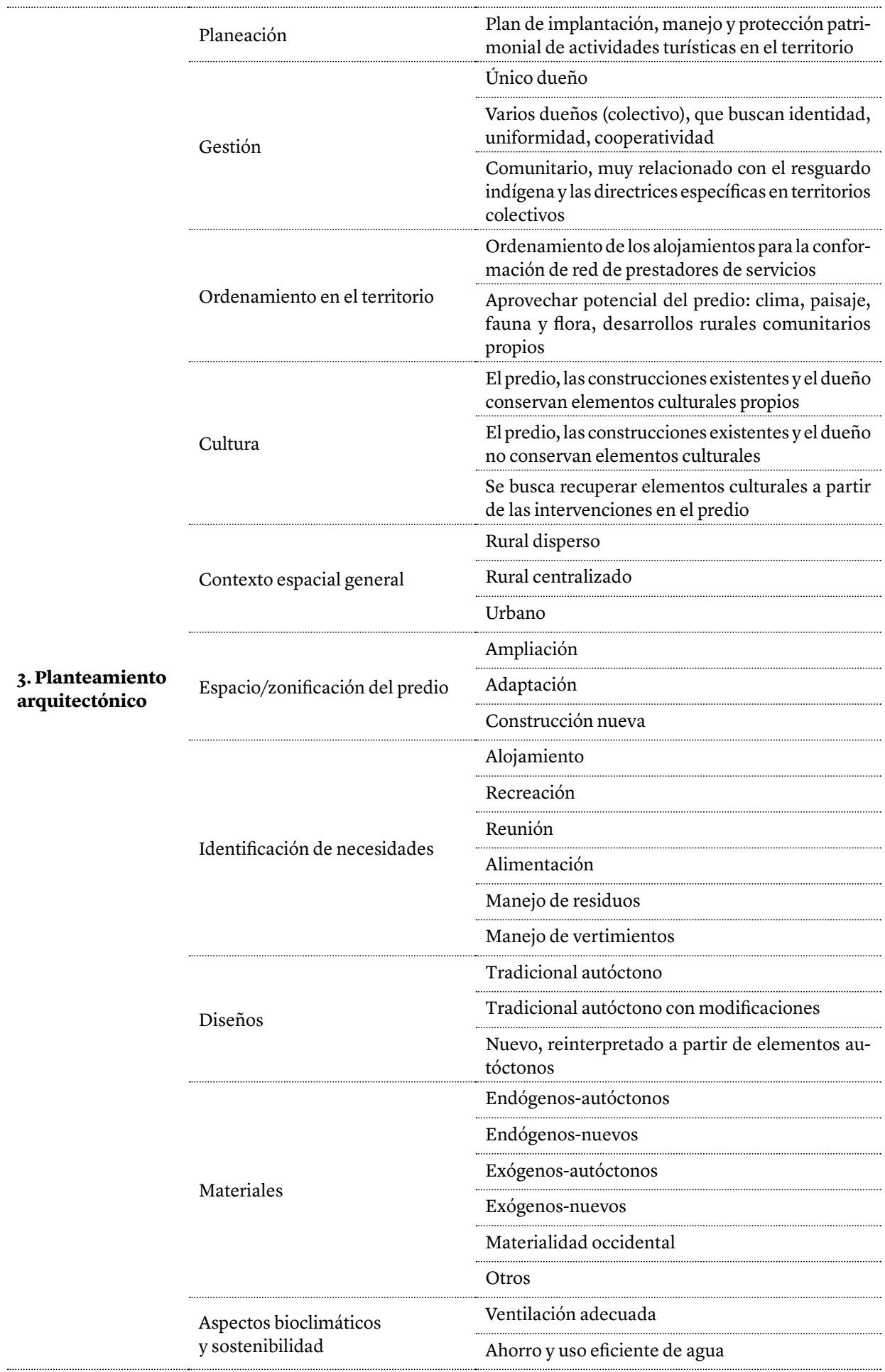




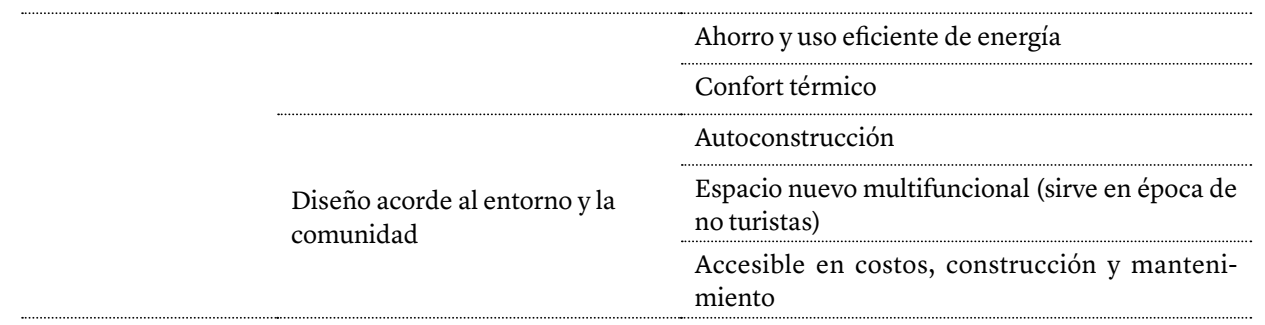

Fuente: elaboración propia

De esta manera, se cuenta con una base que permite identificar los potenciales del predio, así como las necesidades del prestador del servicio. Sin embargo, estos elementos, por sí solos, no son suficientes para la identificación de los determinantes de diseño, por lo que es importante considerar los aspectos normativos colombianos referidos al alojamiento rural.

Las temáticas, en general, buscan establecer el tipo de turismo y de turista que se quiere en los diferentes escenarios territoriales; los aspectos culturales que pueden vincularse y cuáles están restringidos; $\mathrm{y}$, por último, el planteamiento arquitectónico, el cual, en esta fase del proyecto, se desarrolló desde aspectos específicos del diseño del alojamiento turístico. No obstante, hacia el final del proceso se consideró necesario incluir elementos de planeación y gestión, orientados a los aspectos de ordenamiento del territorio en términos de la distribución de los alojamientos rurales y futuros equipamientos, teniendo en cuenta la propiedad de la tierra (privado-colectivo), el potencial del paisaje andino y sus manifestaciones culturales.

\section{Opciones de intervenciones para el desarrollo de alojamiento rural indígena}

A partir de los anteriores criterios, se planteó la recopilación de información en grupos de trabajo, con el objetivo de respetar los derechos a la propiedad, su integridad y a la determinación de su propia forma de desarrollo.

Dentro de los recorridos y las interacciones con la comunidad, se determinaron los siguientes elementos principales, relacionados con el alojamiento, especialmente, y otros servicios que, de una u otra manera, se relacionan con la infraestructura; sin embargo, se registran otros elementos por ser considerados de importancia por la comunidad. 


\section{Alojamiento y otros servicios}

Mediante las visitas a Toribío y Tacueyó, se identificaron como actores principales a los líderes de los grupos de desarrollo turístico de:

1. El cerro Berlín (Toribío): liderado por Álvaro Tenorio, con un grupo de 7 personas.

2. Vereda López (Tacueyó y Grupo Asociativo Mi Finquita): liderado por Marco Tulio Jascue, con un grupo de 8 personas.

En cuanto a la primera temática, "generalidades del turismo", la cual busca identificar las expectativas frente al tipo de turista y turismo, los grupos generaron, como resultado de los encuentros de trabajo, los siguientes enunciados y elementos:

Ser reconocidos como comunidad Nasa que resalta su patrimonio cultural y natural de nuestro territorio (...) es aprovechar y hacer el buen uso de la topografía, mostrar la riqueza de los recursos naturales como: las quebradas, las cascadas, los ríos y las montañas. Esto con el gran compromiso de cuidar y conservar la vida de los recursos de la madre tierra.

Respecto al tipo de turista que la comunidad quiere, afirman que deben ser "turistas que valoren y respeten nuestro acervo cultural", y se hace especial énfasis en el compromiso con el cuidado del medio ambiente: "que sean amantes de la biodiversidad, el medio ambiente, la gastronomía (platos típicos) la cultura e interculturalidad", puesto que "todas las especies de plantas y animales son de importancia cultural y cosmogónico, ya que hacen parte de la gran familia Nasa".

En la segunda temática, "culturales generales", se pretende evidenciar los deseos y restricciones que la comunidad quiere asignar a los aspectos culturales; para ello, se busca recrear todo el patrimonio de la cultura y la búsqueda de alianzas para el desarrollo de las actividades turísticas. De esta manera, se identificaron algunos elementos propios de la cultura, que se relacionan con el patrimonio y se pueden materializar en el territorio por medio de la generación de propuestas en la tercera temática, "planteamiento arquitectónico".

Como requerimiento, se evidencian aspectos de formación en otros idiomas, en servicio al cliente, alojamiento y manejo de alimentos, entre otros. Por parte de los atractivos turísticos, se promueve el recorrido y la observación del territorio, admirar sus paisajes, el agua, la flora, la fauna y, por último, los aspectos culturales relacionados con la manera de interactuar con el territorio. De los rituales más importantes se reconoce al Saakehlu y a la armonización de las personas. 
Como principales actividades que representen un valor cultural para el turista, se menciona, como fundamental, la armonización al visitante y, posteriormente, el conocimiento de la tulpa, "ya que son sitios donde nos reunimos para plantear o concertar las propuestas con los mayores espirituales, esto con el ánimo de estar siempre en equilibrio y armonía con la madre tierra", elaboración de jigras y la música autóctona, elementos que se pueden representar en los diseños arquitectónicos, reinterpretarse y promover su divulgación en el desarrollo de las actividades turísticas. El grupo de trabajo pensó que también se podían elaborar artesanías, principalmente la jigra, la varita del cabildo con la pañoleta de la guardia indígena y los calabazos.

En cuanto a los elementos relacionados con la construcción de alojamientos y otros equipamientos, se promueve fuertemente la utilización de los materiales locales y las técnicas de construcción propias, para divulgación al turista sobre los modos y medios de vida, a partir de la tierra, el barro, la madera y los bejucos como elementos constitutivos de la construcción. Sin embargo, hacen un llamado a la recuperación de los materiales y técnicas propias, "las construcciones locales son de mucha importancia para el desarrollo del turismo, ya que vamos a vivenciar el cuidado, el control y el manejo de los recursos naturales".

Aunque se evidencia un interés por dar a conocer la cultura a partir de su representación en la vivienda, la tulpa, sitios de reunión, senderos y los cultivos (ax tull), consideran importante conservar aspectos intocables como el acceso a sitios sagrados y las plantas sagradas utilizadas en los rituales; también, en repetidas menciones, consideran necesaria la armonización de los visitantes para entrar al territorio, y compartir con la familia y comuneros.

El cabildo busca generar una cohesión frente al uso de materiales locales y diseños propios; sin embargo, las orientaciones que han recibido desde asesores externos o propuestas para el diseño de sus alojamientos, no necesariamente se alinean con las directrices propias, como en el caso de propuestas de alojamiento tipo chalet suizo y la gastronomía no propia para atender al turista. Tal vez, estas ideas fueron orientadas desde asesores que no conocen las tradiciones y la historia de la comunidad en la lucha y la defensa de su territorio.

Para minimizar los impactos del turismo sobre la producción de los alojamientos y los demás equipamientos, de la mano del contacto intercultural que se genera, se busca evitar el cambio de valores materiales e inmateriales por la mercantilización y la manipulación a través de operadores de turismo externos a la comunidad. Un primer paso es buscar alternativas de desarrollo de unidades de alojamiento rural que permitan a la comunidad comenzar a incursionar en el turismo acorde a sus capacidades e intereses. 
En relación con los criterios anteriormente expuestos, se consolidaron diferentes opciones de diseño para alojamientos turísticos en el municipio de Toribío, basados en la correlación y cruces de las temáticas y aspectos ya mencionados. Mediante este ejercicio, surgieron tres opciones de diseño-explicadas más adelante-que brindan la flexibilidad de intervención y adecuación de los espacios existentes, bajo parámetros respetuosos con la tipología arquitectónica y constructiva autóctona del territorio. Igualmente, ofrecenla posibilidad de desarrollo de alojamientos totalmente nuevos que conserven elementos tipológicos de las construcciones tradicionales Nasa-Páez.

\section{Opción 1}

Se puede considerar como una alternativa en la que los habitantes locales tienen la posibilidad de prestar el servicio turístico. Para ello, se adecúan algunas habitaciones para la llegada del visitante, quien, en esta modalidad, "vive" la experiencia total de la vivienda indígena, con todas las variables propias, tales como servicios sanitarios, alimentación y zonas de descanso en el marco mismo de la vida diaria local; en este caso, los sitios de reunión son los mismos que utiliza la familia que presta el servicio. Es la opción más básica que permite probar si la prestación del servicio de alojamiento es compatible con la familia, y si realmente puede llegar a convertirse en una opción de generación de ingresos.

Los criterios para el establecimiento y determinantes de diseño para alojamientos rurales indígenas anteriormente expuestos se toman, de manera general, para el desarrollo de la presente propuesta de alojamiento, enfatizando en algunos aspectos que se consideran de mayor relevancia debido al usuario, tipo de experiencia que se desea brindar y escala de intervención.

Esta primera opción enfatiza en aspectos como las expectativas frente al tipo de turismo en el territorio y tipo de visitante, con el ánimo de proveer una respuesta arquitectónica coherente a un turista multifacético que desea experiencias cercanas al modo de vida tradicional en el territorio. Al igual, enfatiza en el tratamiento de aspectos culturales, espaciales y de diseño, acorde a un desarrollo culturalmente respetuoso y coherente a la escala, desarrollando una respuesta habitacional donde los propietarios entran a adecuar los espacios existentes de la vivienda, con la finalidad de proporcionar habitaciones para la estancia y descanso de turistas, bajo una acomodación sencilla o doble, dependiendo del requerimiento, y haciendo uso compartido de las zonas comunes y de servicio de la edificación, como la unidad sanitaria, la cocina, circulaciones y zonas sociales, lo cual permite al usuario tener una experiencia directa con el modo de vida del habitante local. 
FIGURA 5 | Opción 1: alojamiento inmerso en viviendas tradicionales para uso turístico

1- Habitación para turistas 1

2- Habitación para turistas 2

3-Cocina

4- Baño

5 -Comedor

6- Habitación 1

7-Sala

8- Habitación 2

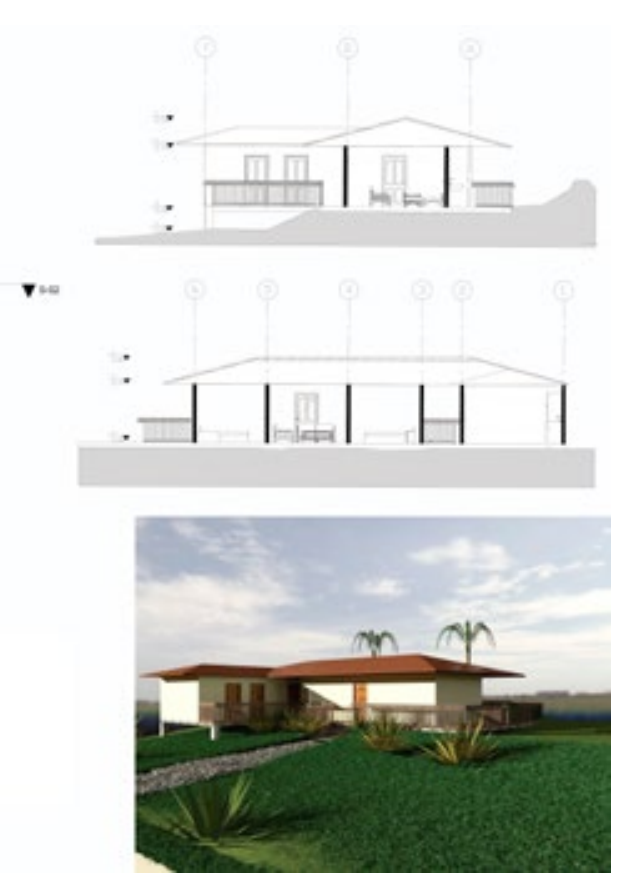

Fuente: elaborado por Juan David González y Valeria Ruiz

\section{Opción 2}

Se construye una habitación con algunas comodidades, como baño privado y, de ser posible, ventanas que permitan admirar el paisaje (opcional), pero en la misma estructura de la vivienda original; aunque el turista comparte los mismos espacios con los dueños de la vivienda, tiene alguna privacidad frente al uso del servicio sanitario.

Dicho modelo retoma, de manera general, los criterios ya planteados, enfatizando en aspectos como expectativas frente al tipo de turismo en el territorio y de visitante, proporcionando un espacio para turistas que viajan en grupo o núcleo familiar y requieren determinado nivel de privacidad en su estancia. Por otra parte, son tomados en cuenta aspectos de planeación, gestión, contexto espacial, materialidad y diseño, acordes al entorno y la comunidad, brindando una solución de alojamiento que proporciona un nuevo espacio anexo a la edificación existente, con una modulación sencilla que busca mantener la tipología y espacialidad presentes en 
la vivienda, al igual que replicar su materialidad y técnica constructiva (bahareque embutido). Este nuevo espacio brinda la facilidad de una acomodación múltiple con capacidad de hasta ocho usuarios y una unidad sanitaria privada que sirva a los mismos. Sin embargo, el uso y aprovechamiento de las zonas sociales, circulación y cocina, continúan siendo compartidos, como parte de la experiencia de habitar en una vivienda local.

\section{FIGURA 6 Opción 2: alojamiento anexo a viviendas tradicionales para uso turístico}

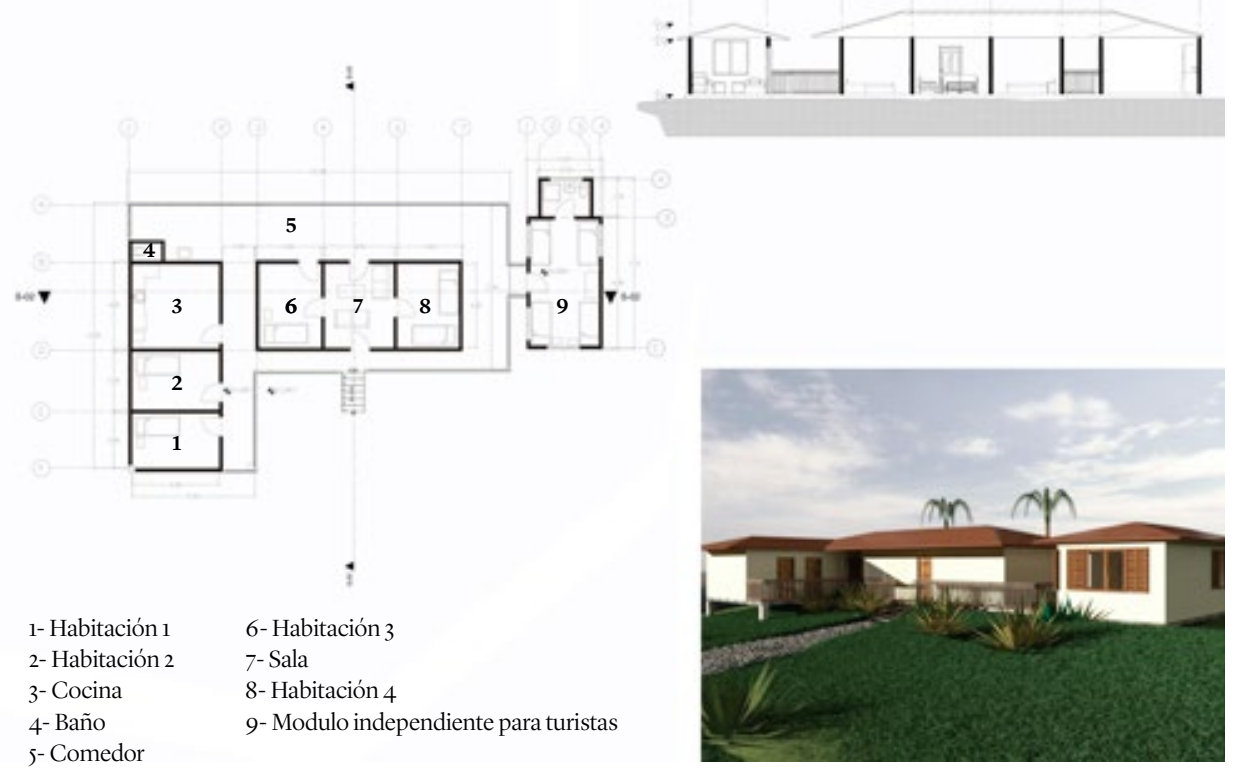

Fuente: elaborado por Juan David González y Valeria Ruiz

\section{Opción 3}

Desarrollo de un módulo de alojamiento (tipo cabaña) con las determinantes de diseño y uso de materiales locales y aprobados por las autoridades del cabildo o resguardo indígena. Este módulo estará totalmente separado de la casa original y puede contar con diversos servicios.

El alojamiento desarrolla múltiples criterios para el establecimiento y determinantes de diseño para alojamientos rurales indígenas, denotando, primordialmente, 


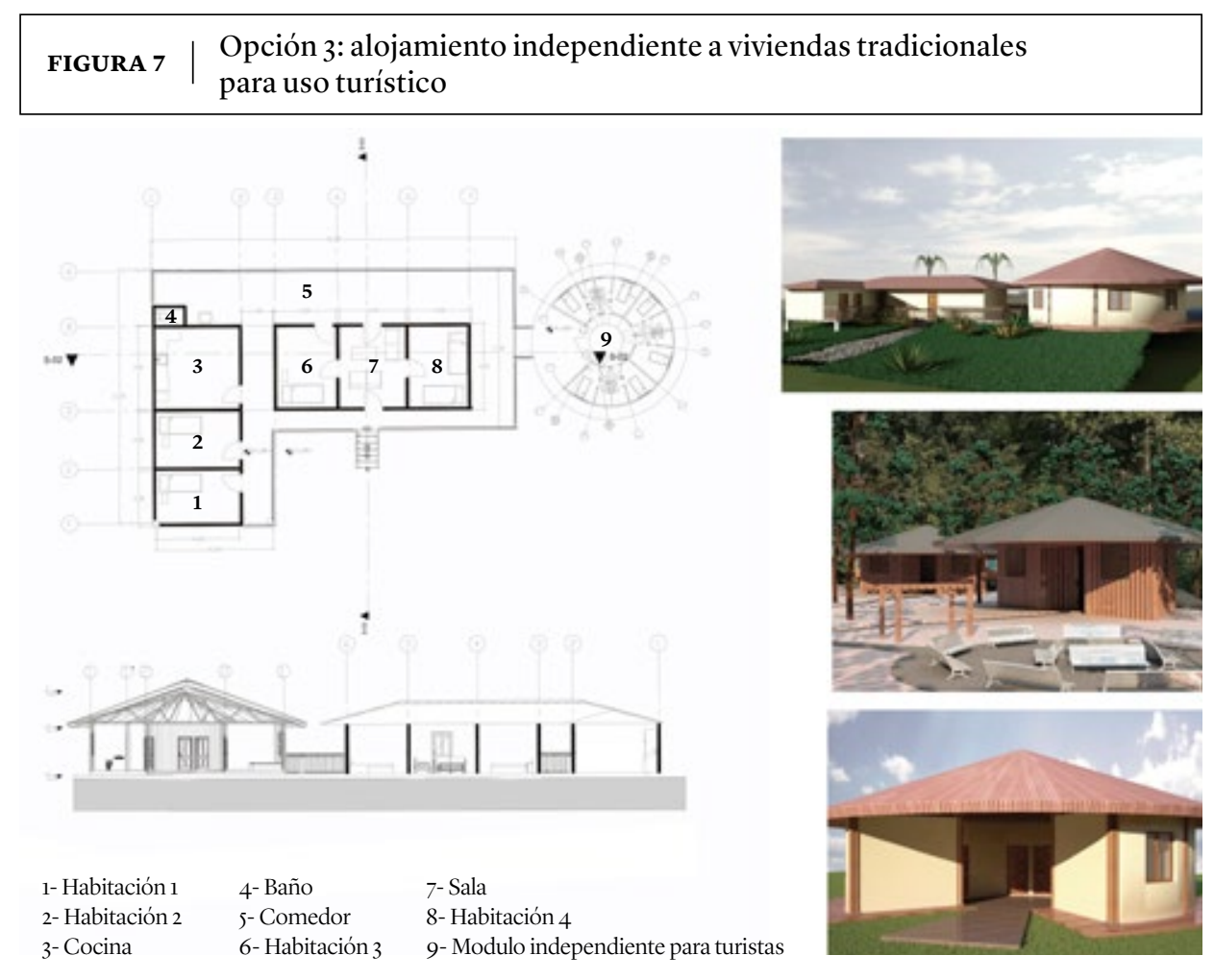

Fuente: Juan David González y Valeria Ruiz, 2017

la implementación de aspectos como expectativas frente al tipo de turismo en el territorio y tipo de visitante, sirviendo a un usuario que requiere espacios dispuestos con comodidad y privacidad, en contacto con la naturaleza y cultura autóctona. Tiene en cuenta aspectos de planeación, gestión, ordenamiento en el territorio, contexto espacial, materialidad y diseño, acordes al entorno y la comunidad, y se presenta como un módulo habitacional totalmente independiente, bajo una composición volumétrica y espacial que busca rescatar la implantación radial presente en las costumbres ancestrales de la comunidad Nasa-Páez.

La vivienda existente se conecta al nuevo módulo mediante senderos y espacios de circulación independientes que abren al hall central del alojamiento, el cual sirve como zona social del módulo y brinda acceso a las habitaciones que están dispuestas al turista. El módulo proporciona cinco habitaciones de acomodación sencilla o doble, acompañado de una unidad sanitaria independiente por alcoba. La materialidad y técnica constructiva del presente alojamiento abre opciones para la implementaciones de edificaciones en madera endémica, que puede ser utilizada en 
la estructura y envolvente de la edificación, o permite su implementación bajo una materialidad y técnica constructiva tradicional, utilizando el bahareque embutido. Conforma un espacio que permite la convivencia en un entorno local y acceso a la cotidianidad de la población nativa, al igual que brinda independencia y privacidad al usuario que exige mayor comodidad.

Esta opción permite que los visitantes compartan la vivencia con la familia receptora, pero que puedan, unos y otros, gozar de privacidad en sus actividades propias.

Estas modalidades, en general, permiten una gradualidad en la inversión económica que representa el atender turistas y generar espacios de calidad, cada una de las opciones puede permanecer en el tiempo y pueden llegar a ser complementarias entre ellas, para así atender a diferentes tipos de turistas.

\section{Conclusiones}

Las alternativas derivadas del posacuerdo abren diversas oportunidades para las comunidades que estuvieron en medio del conflicto armado, por lo que el cambio de imagen de esos territorios es prioritario. El turismo es considerado, en la comunidad, como una opción para explorar y reconocer el territorio por propios y externos; sin embargo, las acciones hasta ahora encaminadas a modelos de negocio no son explícitas frente a las necesidades de diseño arquitectónico basado en la arquitectura vernácula, con signos y significados culturales.

El trabajo con los grupos de turismo del municipio (Cerro Berlín y Grupo Asociativo Mi Finquita) evidenció la necesidad de proponer un instrumento que ordene la toma de decisiones frente a los determinantes de diseño. Para ello, se encontraron tres temáticas: 1) generalidades del turismo; 2) culturales generales; y 3) planteamiento arquitectónico, con 16 aspectos que orientan la participación para el diseño de alojamientos y otro tipo de infraestructura.

El resultado fue de tres opciones de intervención en diseños de alojamientos rurales indígenas, las cuales se extraen del trabajo con la comunidad y se orientan desde la gradualidad, para que la comunidad pueda explorar si el servicio de alojamiento está acorde con sus modos y medios de vida. Estos modelos de alojamiento para turistas y visitantes responden a los requerimientos y dinámicas del turismo en zonas de valor patrimonial y medioambiental, de acuerdo a las exigencias de los diferentes tipos de usuario, y teniendo en cuenta a viajeros particulares, grupos y núcleos familiares, que pueden acceder a diferentes niveles de servicios, comodidad y privacidad.

Presentándose de forma flexible y al alcance de las disimiles condiciones presentes de cada familia o habitante local que desea impulsar la iniciativa, los aloja- 
mientos propuestos brindan opciones de crecimiento y desarrollo que optimizan las condiciones socioeconómicas del habitante y su territorio. Todo esto bajo una mirada holística de las condiciones, la cual debe ser tomada en cuenta para la implementación de un modelo de turismo sostenible y sustentable, desde lo territorial, medioambiental, social, cultural, económico y productivo.

De esta manera, la arquitectura responde a las necesidades de las comunidades rurales indígenas, a partir de diseños con materiales locales y determinantes culturales, además de proponer un esquema gradual que beneficie a la comunidad. La arquitectura se convierte en el engrane entre la cultura tradicional y el futuro del desarrollo socioeconómico de un territorio que desea crecer y consolidarse bajo una mirada positiva a los ojos del país, dejando atrás la imagen de un municipio azotado por el conflicto armado.

Una propuesta pensada desde los habitantes para los habitantes, quienes esperan ver un futuro amable para toda su comunidad y, poco a poco, dejan atrás el tiempo de violencia y proyectan un futuro próspero alrededor del territorio que habitan, el cual esta colmado de múltiples riquezas y condiciones excepcionales que posee la cordillera central colombiana, además de una cultura ancestral, llena de innumerables ritos y prácticas tradicionales de la comunidad Nasa-Páez.

En este contexto, el desarrollo arquitectónico de uso turista servirá para resaltar y habilitar el aprovechamiento de todos los valores naturales y culturales mencionados, de manera positiva, para aquellos que deseen visitar el municipio de Toribío. Se muestra, además, una implementación accesible y maleable a las condiciones de los habitantes, lo que permite un desarrollo paulatino y progresivo concordante al nivel de consolidación de dicha actividad, y respetuoso con el medio ambiente, mediante la preservación de la materialidad (construcción en tierra) y las técnicas constructivas tradicionales, al igual que el resguardo de los principios culturales y cosmogónicos presentes en el territorio, expresados en los diseños propuestos.

\section{Referencias}

Arnoult, Jean-Marie (2010). Cultural Heritage and Tourism: A Complex Management Combination the Example of Mauritania. International Preservation News, 52(1), 18-23.

Asensio, Raúl; Pérez, Beatriz (2012). ¿El turismo es cosa de pobres? Patrimonio cultural, pueblos indigenas y nuevas formas de turismo en América Latina. Tenerife, España: Asociación Canaria de Antropología/PASOS. Recuperado de http://www.pasosonline.org/Publicados/ pasosoedita/PSEdita8.pdf 
Bernal, Martha (2012). Territorialidad nasa en Bogotá: apropiación, percepción y sentido de lugar. Revista Cuadernos de Geografía, 21(1), 83-98.

Bernardino, Susana; Freitas, José. (2017). Local development through social and territorial innovation: An exploratory case study. Revista de Economía Pública, Socialy Cooperativa, 9o(1), 159-187.

Bolnick, Steven (2003). Promoting the culture sector through job creation and small entreprise development (SEED) in SADC Countries: The Ethno-tourism industry. Recuperado de https://www.ilo.org/wcmsp5/groups/public/---ed_emp/---emp_ent/---ifp_seed/documents/ publication/wcms_117681.pdf

Cardet-Fernández, Evelina; González, Yaumara; Palao, Rosa (2017). Turismo y patrimonio a favor del desarrollo local, para diferenciar el destino Holguín. Retos Turísticos, 16(1). Recuperado de http://retos.mes.edu.cu/index.php/retojs/article/view/251

Centro de Educación, Capacitación e Investigación para el Desarrollo Integral de la Comunidad (2015). Guía para estructurar y desarrollar procesos investigativos en el territorio Nasa de Toribio, Tacueyó y San Francisco. Texto de construcción Colectiva, Investigación CECIDIC. Toribío: CECIDIC.

Docentes de la comunidad Nasa (2014). Leyendo la vida nasa. Bogotá: Ministerio de Educación Nacional.

Giedelmann, Mónica; Rueda, Oscar (2013). Discursos patrimoniales que orientan la gestión del patrimonio cultural en los planes de desarrollo del departamento de Santander-Colombia (2008-15). Revista Memoria y Sociedad, 17(35), 106-123.

Herrera, Alexander (2017). Turismo patrimonial, identidad y desarrollo en el Perú. Indiana, 34(1), 199-230.

Levalle, Sebastián; Levin, Luciana (2011). Cuando la investigación se vuelve minga de pensamientos, los pueblos indígenas del sur colombiano y su lucha por la educación propia. Asociación de cabildos indígenas nasa Çxhãçxhã. Recuperado de http://tierradentro.co/ Cuando-la-investigacion-se-vuelve

Llontop, Claudia (2017). La relación entre gestión y turismo, basada en la experiencia del visitante. Revista Turismo y Patrimonio, 11(1), 77-93.

Maldonado, Carlos (2006). Turismo y comunidades indígenas: impactos, pautas para autoevaluación y códigos de conducta. Recuperado de http://www.ilo.org/wcmsp5/groups/public/--ed_emp/---emp_ent/---ifp_seed/documents/publication/wcms_117521.pdf

Marín, Gustavo; García, Ana; Daltabuit, Magalí (2012). Turismo, globalizacióny sociedades locales en la península de Yucatán, México. Tenerife, España: Asociación Canaria de Antropología/ PASOS. Recuperado de http://www.pasosonline.org/Publicados/pasosoedita/PSEdita7.pdf 
Ministerio de Comercio, Industria y Turismo (2015a). Patrimonio arquitectónico. Recuperado de http://www.mincultura.gov.co/areas/patrimonio/patrimonio-cultural-inmueble/patrimonio-arquitectonico/Paginas/default.aspx.

Ministerio de Comercio, Industria y Turismo (2015b). Turismo, pazy convivencia. Recuperado de http://www.mincit.gov.co/minturismo/publicaciones/34045/turismo_paz_y_convivencia

Ministerio de Comercio, Industria y Turismo (2017). MinComercio abre convocatoria para proyectos de turismo comunitario. Bogotá: MINCIT. Recuperado de http://www.mincit. gov.co/publicaciones/38361/mincomercio_abre_convocatoria_para_proyectos_de_turismo_comunitario

Ministerio de Cultura (2010). Nasa Páez, la gente de agua. Bogotá: Ministerio de Cultura.

Ojeda, José (octubre, 2004). Turismo en el espacio ruraly patrimonio histórico: desarrollo socioeconómico de las ciudades medias andaluzas. Trabajo presentado en I Congreso Internacional Patrimonio, Desarrollo Rural y Turismo en el Siglo XXI, Osuna, España.

Organización de las Naciones Unidas para la Educación, la Ciencia y la Cultura (2017). Patrimonio Cultural. Recuperado de http://www.unesco.org/new/es/santiago/culture/world-heritage/

Ospina-Niño, José (2017). Paisaje y territorio en la playa Juan de Dios, Bahía Málaga, Pacífico colombiano (2005-2016): una aproximación desde la nueva geografía del turismo. Cuadernos de Geografia, 26(2), 31-52.

Pedersen, Arthur (2005). Gestión del turismo en sitios del patrimonio mundial: manual práctico para administradores de sitios del patrimonio mundial. Recuperado de http://unesdoc.unesco. org/images/oo12/o01286/128679s.pdf

Pereiro, Xerardo (2013). Los efectos del turismo en las culturas indígenas de América Latina. Revista española de antropología americana, 43(1), 155-174.

Velazco, María (2009). Gestión turística del patrimonio cultural: enfoques para un desarrollo sostenible del turismo cultural. Revista Cuadernos de Turismo, 23(1), 237-257.

Zanirato, Silvia; Tomazzoni, Edgar (2015). Patrimonio, turismo y transfiguraciones en las relaciones identidarias. El Pelourinho (Salvador-Bahia) y Porto Rico (Paraná), Brasil. Estudios y Perspectivas en Turismo, 24(2), 222-243. 